Journal of Advanced College of Engineering and Management, Vol. 5, 2019

\title{
SOLAR WATER PUMPING IN ENERGY, WATER AND FOOD NEXUS OF NEPAL
}

\author{
Ramesh Ranabhat ${ }^{1}$, Sundar Bahadur Khadka ${ }^{2}$ \\ ${ }^{1}$ Mechannical Department, Institute of Engineering, Pulchowk Campus, T. U, Nepal \\ Email Address: ramesh.ranabhat@ioe.edu.np \\ ${ }^{2}$ Alternative Energy Promotion Center, Khumaltar, Nepal \\ Email Address: sundar.khadka@aepc.gov.np
}

\begin{abstract}
Agricultural based country Nepal has sufficient arable land.Even though sufficient water sources for the irrigation, farmers are fully reliant on the monsoon. More over only about 18 percent of the total cultivated land receives year round irrigation. More than half of the population have less than 0.5 hectare with average land holding of 0.85 hectare. With this intensive care can give to their farm. But only a season they are cultivated their land.In this context about seventy one thousand tons of food deficit in the country annually. But rapidly declining costs and technology improvements encourage to adopt solar based systems for the irrigation projects. So that are interested to supplement their income through growing vegetables in commercial scale with changing crop pattern through irrigation. Integrated approach for Energy-Water-Food would be essential for development.
\end{abstract}

Key words: Nexus, crop pattern, irrigation

\section{Introduction}

Nepal is an agro-based nation with its total area of 14,718,100 Ha.b Out of 2.7 million hectares of agricultural land in Nepal, only $1.7 \mathrm{Mha}$ have irrigation facilities. Which means only about $12 \%$ land is potential to irrigate through surface and ground water during the monsoon season only1. In other way about $30 \%$ can be irrigated during the winter season, but only about $18 \%$ of the total cultivated land receives year-round irrigation2. It shows the importance of irrigation for crop production in Nepal. However, agriculture is a mainstay of the economy of Nepal and supporting the livelihoods of most of the population. But Livelihoods based on agriculture are vulnerable due to the monsoon climate and the topography. Agriculture sector has its own importance and value for the nation. It is interlinked with gross domestic product(GDP). Most of the governments talked about the exponential growth of this sector earlier. But the economic growth rate recorded above five percent in FY 2007/08 and FY 2013/14, but the rate remained below five percent in other fiscal years. The economic growth rate of the country in past decade averaged 3.8 percent at basic prices. But, the average growth rate of agriculture sectors stood at 2.9 only. Anyway agricultural sector occupy the majority in the GDP of the nation. The table1 below shows the sectorial weightage and average economic growth or the country in last decade.

Table 1: Economic growth in last decade(percentage)

\begin{tabular}{|c|c|c|c|c|c|c|c|c|c|c|c|}
\hline 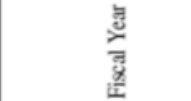 & ह్రి & ڤ్రి & $\begin{array}{l}\text { ఫ్ } \\
\text { ఫ్ }\end{array}$ & 옳 & 흘 & $\stackrel{\cong}{\equiv}$ & 옳 & 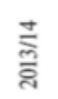 & $\frac{n}{\frac{2}{2}}$ & $\frac{\infty}{\frac{\pi}{2}}$ & $\frac{\mathrm{g}}{\mathrm{g}}$ \\
\hline Agriculture & 1.0 & 5.8 & 3.0 & 2.0 & 4.5 & 4.6 & 1.1 & 4.5 & 0.8 & 1.3 & 2.9 \\
\hline Non Agriculture & 4.4 & 5.9 & 4.3 & 5.0 & 3.6 & 4.5 & 5.0 & 6.4 & 3.1 & 0.6 & 4.3 \\
\hline Industry & 3.9 & 1.7 & -0.6 & 4.0 & 4.3 & 3.0 & 2.7 & 7.1 & 1.5 & -6.3 & 2.1 \\
\hline Service & 4.5 & 7.3 & 6.0 & 5.8 & 3.4 & 5.0 & 5.7 & 6.2 & 3.6 & 2.7 & 5.0 \\
\hline Economic Growth & 2.75 & 5.8 & 3.9 & 4.26 & 3.85 & 4.61 & 3.76 & 5.72 & 2.32 & 0.77 & 3.8 \\
\hline
\end{tabular}

(source: Central Bureau of Statistics) 
The main region behind the quite low growth of the agriculture in FY 15/16is decline in production of main crops. Due to lengthening drought and adverse weather situation, production of paddy which accounts top share in overall agriculture production has declined by 10.2 percent, while that of second main crop wheat production has dropped by 5.0 percent. On the contrary production of other crops including that of maize by 4 percent, potato by 4.5 percent and vegetables by 5.0 percent increased(economic survey 2015-16 GON).

From above statics it is clearly seen the importance of the water and energy management for the increment of the productivity. In another word proper technology and crops selections with the land is essential. In another word food and water are essential for human existence and energy is the key to human development. Access to these resources and their sustainable management are the basis for sustainable development. Recognizing that efficient use of these limited or declining resources is essential to sustainability, the global community has turned its attention to the concept of the food, water, and energy nexus ${ }^{4}$. The following schematic diagram focus on the connections of the subsets each other.

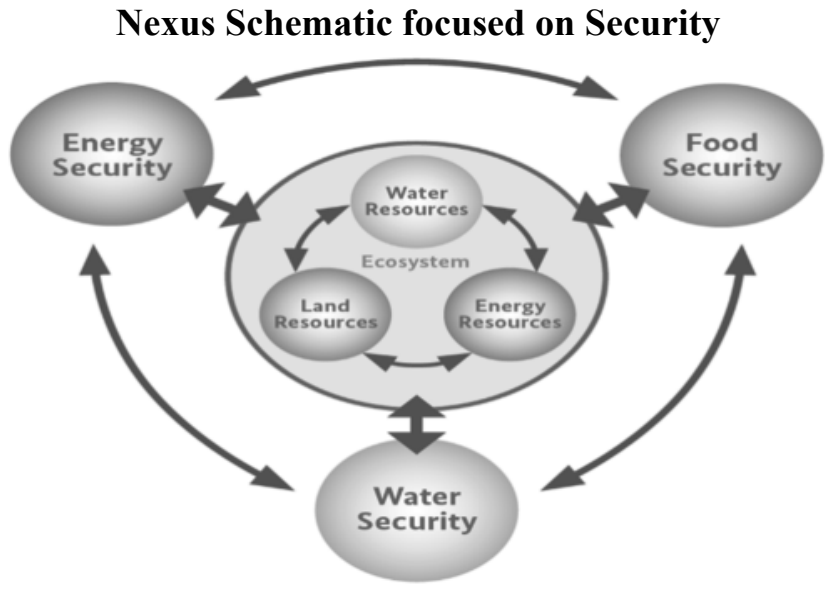

Fig 1: Inter-linkages Among and Between Natural Resources and Human Securities (source: GIZ September 2017)

\section{Energy Food Water Situation in Nepal}

The approach to the energy, water, and food nexus normally depends on the government market policy. In general government basically focused on drinking water project only. But it is interlinked with food and energy systems too. Equally from a food perspective energy and water are inputs. In indications the association of energy food and water. The following figure illustrate the present situation of the nexus briefly. The figures in each subset are not sufficient for the prosper development. 


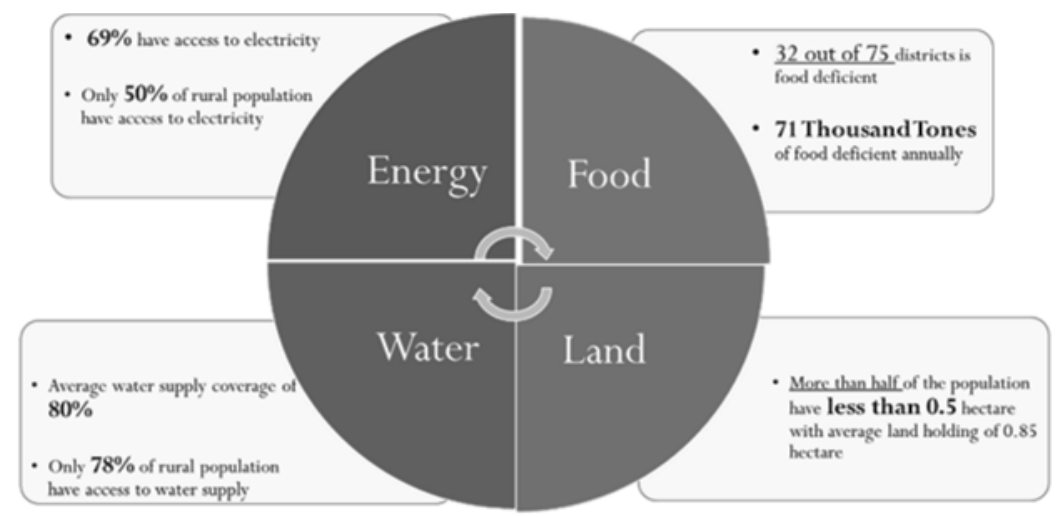

Fig 2: Energy Food Water situation in Nepal

\subsection{Availability and Security of Food}

Individual household level have their own traditional farming methods form their ancestor. But they do not recognize about the physical availability and productivity of the soil for the respective items yet. Which is the major cause for the deficit of the food in the household levels. They became compelled for the own production supplemented by market purchases. The table below shows the fluctuating trends of cereals production.

Table 2: Trends in cereals production in Nepal on a per capita basis, 2000-13

\begin{tabular}{|c|c|c|c|c|c|c|c|c|}
\hline & \multicolumn{3}{|c|}{ Average values (kg) } & \multicolumn{2}{|c|}{ Percent change } & \multicolumn{3}{|c|}{ Growth rate, \% p.a. } \\
\hline & 2001-03 & 2005-07 & 2011-13 & $\begin{array}{r}2013 \text { over } \\
2001 \\
\end{array}$ & $\begin{array}{r}2013 \text { over } \\
2006 \\
\end{array}$ & $\begin{array}{r}2001 \text { to } \\
2013 \\
\end{array}$ & $\begin{array}{r}2001 \text { to } \\
2006 \\
\end{array}$ & $\begin{array}{r}2007 \text { to } \\
2013 \\
\end{array}$ \\
\hline Paddy & 177 & 164 & 174 & -1 & 6 & -0.5 & -0.7 & 1.9 \\
\hline Maize & 65 & 71 & 78 & 20 & 9 & 1.7 & 2.0 & 1.0 \\
\hline Wheat & 53 & 59 & 66 & 24 & 13 & 1.8 & 2.6 & 2.1 \\
\hline Potatoes & 61 & 76 & 97 & 57 & 27 & 4.7 & 6.1 & 3.9 \\
\hline Lentils & 6 & 7 & 8 & 27 & 22 & 1.7 & 0.9 & 5.1 \\
\hline Mustard & 6 & 6 & 6 & 3 & 3 & 0.0 & 0.0 & 0.7 \\
\hline Soybeans & 1 & 1 & 1 & 38 & 29 & 2.8 & 1.9 & 5.3 \\
\hline Cereals total $1 /$ & 233 & 236 & 257 & 10 & 9 & 0.7 & 0.8 & 1.7 \\
\hline
\end{tabular}

$1 /$ Cereals total is the sum of paddy, maize and wheat, with paddy in rice equivalent (with a conversion rate of 0.65 ).

(source: Bureau of Statistics,2016)

There is ups and downs trend in cereal production since 2000. In overall it has been positive for maize, wheat and cereals as a whole but negative for paddy until around2008. Which is quite positive for the recent years. The table also shows good performance for potatoes, soybeans and lentils. But fluctuations of production around the trends leads to be increasing in more recent years. Therefore identifying the suitable product for the land boost domestic productivity. Ultimately scientific farming will improved aggregate food situation in the country.

\subsection{Current status of vegetable market}

Only 17 percent of Nepal's land is arable, and productivity is low due to structural impediments, including poor road infrastructure and small-scale farming. As a result, Nepal imports a significant amount of food products ${ }^{8}$. But vegetables and fruits are the cash crops generally cultivated to sell for the generating profit. In modern day, vegetable farming is done not just for the consumption in the family but also for income-generating purposes. Moreover vegetable crops require a number of techniques to be used to optimize the yield. According to the Central Bureau of Statistics (2009-10) \& 
Ministry of Agriculture and Cooperatives (MoAC), vegetable crops are cultivated in only 7.3 percent of the total cultivable land in Nepal. In recent days the community farming are ongoing as pilot projects. The successful stories creates the positive vibes in agricultural sector. It occupies the significant share of the production in total worth of vegetables which is 8.8 percent of the country's GDP.As supply or production area increases per capita vegetable consumption has also increased to $105 \mathrm{~kg}$ from $60 \mathrm{~kg}$ over last two decades. Vegetables crops are cultivated in 232,295 hectares of cultivable land by 3,243,521 vegetable holdings reported in Nepal. According to the geographic regions vegetable productions in the Terai alone stands 55\% whereas mid-hill and high hills were recorded 40 percent and 5 percent respectively. Never the less 39 percent contribution from the household consumption recorded 1,100,710 metric tons. Whereas $1,719,818$ metric tons about 61 percent are the total sale contribution among 2,820,527 metric tons total vegetable production in FY2009-10. Furthermore vegetables and fruits imported from India accounted for 27 percent of sales at the Kalimati9(2014-15). It indications still there is the huge potential for the local production.

\subsection{Solar pumping as technological approach}

The rapidly declining costs and technology improvements encourage to adopt solar based systems. Favorable intensity of solar insolation and average sunshine hours are the fundamentals for the solar based projects. On average Nepal has 6.8 sunshine hours per day, i.e. 2,482 sunshine hours per year with the intensity of solar insolation ranging from 3.9 to $5.1 \mathrm{kWh} / \mathrm{m} 2 /$ day(Nepal-Solar-Energysociety). Which is quite fair for the solar farming and the irrigation projects. Simple, reliable, cost competitive, and low maintenance modern solar water pumping systems are available in the market. Additionally solar powered irrigation pumps (SPIPs) are a proven technology, small and medium scale solar water pumping systems are more economical to operate than diesel in the rural off grid areas. (Perspectives of Solar Pumping for Irrigation in Nepal, MadhavBelbase ). And solar pumping can potentially be a game changer in Nepal's irrigation sector by providing clean irrigation to millions of farmers. Where they can cultivate cash crops, including potatoes, oilseeds, pulses, vegetables and fruits and many more.

\subsection{Technological Intervention Connecting the Nexus}

Fundamental of the sustainable energy access are availability, affordability and accessibility. For the rural area where the grid line is not available only the renewable energy can support. Alternative Energy Promotion Center (AEPC) is the focal institution for promotion and implementation of renewable energy based technologies. The institution has supported implementation of over 200 photo voltaic pumping system (PVPS) for drinking in rural Nepal providing access to clean water to over 100,000 rural individuals. These projects provide water services to communities by lifting water ranging from 50 to 500 meters. It busted up the quality of life in rural area. Besides AEPC has developed standards and guidelines for design, construction and implementation of PVPS including drinking, irrigation and multiuse of water. Renewable energy based lighting, cooking are quite familiar than productive end use solutions in the present context of rural area. Furthermore technological interventions like efficient drip irrigation, sprinkler technology promotion is vital for the annexes of solar pumping. AEPC continuously assess gaps in technology and policy to update the policy and improve effectiveness of its services. The upfront cost of these technologies are quite high for the low income people in rural area. therefore to deal with this thereis subsidy and mechanism for solar PVPS for Drinking, Drinking and Irrigation in Rural Energy Policy 2006 and RE Subsidy Delivery Mechanism 2016. Maximum subsidy amount of up to $60 \%$ of the total costs but not exceeding NRs. 1,500,000 per system will be provided for PV pumping system for drinking water managed by community or private company. An additional subsidy of NRs. 4,000 per household will be provided to the "targeted beneficiary groups." Similarly maximum subsidy amount of up to $60 \%$ 
of the total costs but not exceeding NRs. 2,000,000 per system will be provided for PV pumping system for irrigation of agricultural land managed by community or private company. It shows policy focus on community based irrigation systems is not well implemented in the country. Integrated approach for Energy-Water-Food would be essential for development.

\section{Comparative Analysis of Traditional and Solar Pumping Irrigation}

Nine individual household and eight groups of framer in six Terai districts had adopted cash crops after the installation of Pump. From the report it have been notice that they all changes their farming crops. Before installation of Pump, each households were producing traditional crops: Maize, Rice, Wheat, Oilseed, Lentil, Potato etc. After installation of Pump, all households started producing vegetables in some part of their land. Major types of vegetables produced by farmers are cash crop for example Cauliflower, Cabbage, Bottle Gourd, BitterGourd, Tomato, Cucumber, Chilly, Long Bean, Brinjal, Okra etc. However, due to heavy monsoon and flooding, rice planting is continued in monsoon season in pump irrigated land. Tangible benefits have been experienced by farmers from vegetable production. The figure below exhibits the comparative cropping pattern after the pump installation and before.

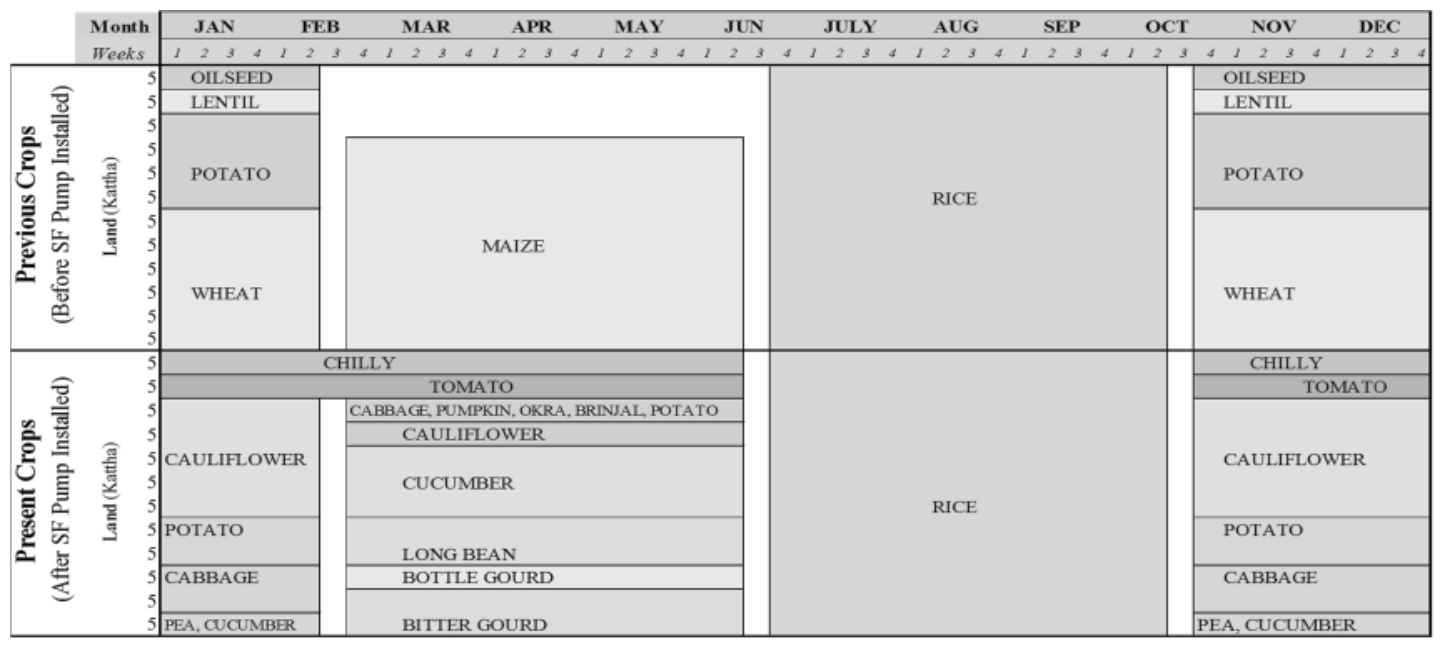

Figure 3: Cropping pattern before and after installation of pump

(Source: Renewable world)

For the particular case of 3.2 kattha land area annual cost for pumping system considering life cycle cost NRs. 12,000 were taken in life span of 2o years. They considered annual cost for land lease and annual cost for agricultural inputs were NRs. 10500 and NRs. 136,029 respectively. Sum total of these values NRs. 158,529 were for the vegetable production with pump irrigation facilities. Whereas only NRs. 41724 for the traditional irrigation system. It includes annual cost for agricultural inputs NRs. 31224 and the same amount NRs. 10500 for land lease as in pumping irrigation. But there were no cost for the pumping facility in the traditional system. In this context benefited value from agricultural production in traditional system NRs. 41850 and in pump system NRs. 339176 were found. Hence the pump irrigation system was far beneficial with $\mathrm{B} / \mathrm{C}$ ratio 2.13 value from the traditional irrigation system. (Source: Renewable world)

\section{Conclusions and Recommendations}

From above facts and figures there is strong connections among the water, food and energy sector. The fundamentals for the agricultural production are still not in good position. The consequences of 
which agriculture base country imported the agricultural product.There is enough fertile land for the agricultural farming. Most of the farms are cultivated only for a season in a traditional manner. The proper management of land with solar pumping facilate and scientific selections of crops results the huge increment in the productivity. This creates the direct and indirect jobs which boosted the GDP of the country. The economic growth rate of the country in past decade was 3.8 percent in average at basic prices. Form the experienced projects above B/C ratio found was around 2.13. With this reference the GDP growth rate might be above 7 percent. Which ultimately strengthen the water food and energy nexus. This is the quite positive vibes for the country development activity.

Farmer's interest to supplement their income through growing vegetables in commercial scale was found. Nonetheless they do not know about the selection criteria of the crops with their locations and climatic factors. To cope with these factors and accelerate farmer's interest the district agricultural development office can works as pioneer. In this concern one of the first priorities of farmers is to have access to cost-effective and reliable small scale irrigation technology. In addition integrated approach for irrigation, crop pattern and efficient water management contributed to significant increase in productivity and income of the household. However conducive policy, environment supporting small and individual PVPS is essential as more than 50 percent population are small landholder. In addition government should focus to identify the gaps and huddles of the agricultural development. For example increase in subsidy for upfront cost of the technology might work. Similarly soft lone, insurance policy for the agricultural items and security of the market with good price encourage the sector. In addition value add technology for the product and storing provision lure the individuals.

\section{References}

1. https://cdkn.org/resource/effectiveness-resilience-small-medium-irrigation Nepal/? loclang $=$ en $\_b$

2. "Framework for effectiveness and resilience of small- and medium-scale irrigation systems in Nepal"

3. CERD (2007) Development of database for irrigation development in Nepal'. Kathmandu: Centre for Engineering Research and Development, Department of Irrigation.

4. https://www.sciencedirect.com/science/article/pii/S1462901114000239

5. http://www.sasecrtn.edu.np/index.php/en/resources/usefulinfo/how-to-grow-harvest-food-cashcrops/vegetable-production-and-consumption-in-nepal

6. 5_lissons_Learnt_Final_Report-final, Nexus into sectoralpolocoes and instructions in the arabRegion, giz September 2017

7. "Food and nutrition security in Nepal: a status report", FAO project,Central Bureau of Statistics, Kathmandu(2016)

8. https://www.export.gov/article?id=Nepal-Food-and-Dairy-Products

9. http://www.freshplaza.com/article/135302/Nepal-27-procent-of-fruit,-veg-imported-from-India

10. Bajracharya and Shrestha, 2011S.R. Bajracharya, B. Shrestha (Eds.), "The status of Glaciers in the Hindu Kush-Himalayan Region", ICIMOD, Kathmandu (2011)

11. https://www.irena.org/-/media/Files/IRENA/Agency/Events/2014/Nov/10/Nepal-Solar-EnergySociety. "Application of Clean Energy in Nepal: Prospects and Problems", DrJaganNath Shrestha 